\title{
Transcription Factor MafB
}

National Cancer Institute

\section{Source}

National Cancer Institute. Transcription Factor MafB. NCI Thesaurus. Code C97673.

Transcription factor MafB (323 aa, $\sim 36 \mathrm{kDa}$ ) is encoded by the human MAFB gene. This protein plays a role in both the modulation of transcription and the negative regulation of erythrocyte differentiation. 